\title{
Электрофизические свойства кристаллов ZnSe, легированных переходными элементами
}

\author{
(C) Ю.А. Ницук, Ю.Ф. Ваксман \\ Одесский национальный университет им. И.И. Мечникова, \\ 65082 Одесса, Украина \\ E-mail: nitsuk@onu.edu.ua
}

(Получена 11 ноября 2016 г. Принята к печати 21 ноября 2016 г.)

\begin{abstract}
Проведены исследования электропроводности и фотопроводимости кристаллов $\mathrm{ZnSe}$, легированных ионами переходных элементов. Показано, что легирование кристаллов селенида цинка примесями $3 d$-элементов не приводит к образованию электрически активных уровней этих примесей. Вместе с тем внедрение исследуемых примесей в катионную подрешетку приводит к образованию электрически активных собственных дефектов. Установлено, что кристаллы ZnSe, легированные $\mathrm{Ti}, \mathrm{V}, \mathrm{Cr}, \mathrm{Fe}, \mathrm{Co}, \mathrm{Ni}$, обладают высокотемпературной примесной фотопроводимостью. Предложены механизмы фотопроводимости в исследуемых кристаллах. По положению первой ионизационной полосы фотопроводимости определены энергии основных состояний $3 d^{2+}$-ионов в кристаллах селенида цинка.
\end{abstract}

DOI: $10.21883 /$ FTP.2017.06.44557.8448

\section{1. Введение}

Кристаллы селенида цинка, легированные переходными элементами, получили широкое применение в качестве материалов для активных сред и пассивных затворов лазеров среднего инфракрасного (ИК) диапазона. На основе кристаллов $\mathrm{ZnSe}: \mathrm{Cr}$ и $\mathrm{ZnSe}: \mathrm{Fe}$ успешно реализована эффективная лазерная генерация $[1,2]$. Применение этих кристаллов в электролюминесцентных структурах ограничено отсутствием исследований их электрофизических свойств. Имеющиеся работы посвящены исследованию электропроводности и ионизационных переходов кристаллов $\mathrm{ZnSe}: \mathrm{Cr}[3,4]$ и $\mathrm{ZnSe}: \mathrm{Cu}[5]$.

В данной работе представлены комплексные исследования электропроводности и фотопроводимости кристаллов $\mathrm{ZnSe}$, легированных $\mathrm{Ti}, \mathrm{V}, \mathrm{Cr}, \mathrm{Fe}, \mathrm{Co}, \mathrm{Ni}$. Целью данной работы является установление природы центров, ответственных за электропроводность и фотопроводимость кристаллов $\mathrm{ZnSe}$, легированных $\mathrm{Ti}, \mathrm{V}, \mathrm{Cr}$, $\mathrm{Fe}, \mathrm{Co}, \mathrm{Ni}$.

\section{2. Методика эксперимента}

Исследуемые образцы были получены методом диффузионного легирования примесями переходных элементов исходно чистых монокристаллов $\mathrm{ZnSe}$. Нелегированные кристаллы получены методом свободного роста на подложке монокристаллического $\mathrm{ZnSe}$, ориентированной в плоскости (111). Технология легирования и оптические свойства исследуемых кристаллов детально описаны в [6-10]. Концентрация легирующих примесей определялась по кулоновскому смещению края фундаментального поглощения в [6-9].

Установлено, что переходные элементы в исследуемых кристаллах $\mathrm{ZnSe}$ локализуются в узлах цинка в зарядовом состоянии +2 . Это подтверждается исследованиями оптической плотности и фотолюминесценции, которые обусловлены оптическими переходами, происходящими в пределах двухзарядных ионов переходных элементов [6-10], а также теоретическими расчетами энергетических состояний двухзарядных ионов переходных элементов в кристаллах селенида цинка [6,7].

Для проведения электрофизических измерений на исследуемые кристаллы наносились электрические индиевые контакты. Вжигание индия осуществлялось при температуре $600 \mathrm{~K}$ с использованием вакуумной установки ВУП-4. Омичность контактов контролировалась измерениями вольт-амперных характеристик. Тип проводимости определялся по знаку термоэдс. Удельное сопротивление $\rho$ измерялось методом Ван-дер-Пау.

Спектры фотопроводимости измерялись с использованием монохроматора МУМ-2 с дифракционной решеткой 1200 штр/мм. Источником света служила галогеновая лампа. Мощность светового потока лампы поддерживалась постоянной на различных длинах волн посредством регулировки тока накала лампы.

\section{3. Анализ механизма электропроводности}

Нелегированные кристаллы $\mathrm{ZnSe}$ характеризуются высоким удельным сопротивлением, $\rho=10^{8} \mathrm{OM} \cdot \mathrm{cm}$, и обладают компенсированной электронной проводимостью. Исследованиями температурных зависимостей темнового тока установлено, что проводимость свежевыращенных кристаллов контролируется донорами с энергией активации 0.66 эВ. Донорам с такой энергией активации соответствуют межузельные атомы цинка. Компенсация проводимости в нелегированных кристаллах объясняется присутствием в них собственных дефектов акцепторной природы - вакансий цинка.

Исследования термоэдс показали, что кристаллы $\mathrm{ZnSe}$, легированные $\mathrm{Ti}, \mathrm{V}, \mathrm{Cr}, \mathrm{Fe}, \mathrm{Co}, \mathrm{Ni}$, сохраняют электронный тип проводимости. 
Таблица 1. Электрофизические характеристики кристаллов $\mathrm{ZnSe}$, легированных переходными металлами

\begin{tabular}{c|c|c|c|c|c|c|c}
\hline Тип кристалла & $\mathrm{ZnSe}$ & $\mathrm{ZnSe}: \mathrm{Ti}$ & $\mathrm{ZnSe}: \mathrm{V}$ & $\mathrm{ZnSe}: \mathrm{Cr}$ & $\mathrm{ZnSe}: \mathrm{Fe}$ & $\mathrm{ZnSe}: \mathrm{Co}$ & $\mathrm{ZnSe}: \mathrm{Ni}$ \\
\hline$\rho$, Ом·см & $10^{8}$ & $2 \cdot 10^{6}$ & $6 \cdot 10^{6}$ & $6 \cdot 10^{5}$ & $3 \cdot 10^{6}$ & $5 \cdot 10^{5}$ & $2 \cdot 10^{6}$ \\
$n, \mathrm{~cm}^{-3}$ & $6 \cdot 10^{7}$ & $1.1 \cdot 10^{11}$ & $5 \cdot 10^{8}$ & $1.1 \cdot 10^{9}$ & $6 \cdot 10^{10}$ & $4.3 \cdot 10^{11}$ & $1.5 \cdot 10^{11}$ \\
$N_{d}, \mathrm{~cm}^{-3}$ & $2.0 \cdot 10^{8}$ & $4 \cdot 10^{10}$ & $2 \cdot 10^{11}$ & $5 \cdot 10^{10}$ & $5.2 \cdot 10^{10}$ & $5 \cdot 10^{10}$ & $1.3 \cdot 10^{10}$ \\
$N_{a}, \mathrm{~cm}^{-3}$ & $1.4 \cdot 10^{8}$ & $8 \cdot 10^{9}$ & $1.5 \cdot 10^{11}$ & $4 \cdot 10^{10}$ & $5.0 \cdot 10^{10}$ & $3.8 \cdot 10^{10}$ & $1 \cdot 10^{10}$ \\
$\left(E_{c}-E_{d}\right)_{\exp }$, эB & 0.66 & 0.65 & 0.65 & 0.65 & 0.65 & 0.65 & 0.65 \\
$\left(E_{c}-E_{d}\right)_{\text {calc }}$, эB & 0.64 & 0.64 & 0.65 & 0.64 & 0.66 & 0.65 & 0.67
\end{tabular}

Легирование кристаллов ZnSe примесями $\mathrm{Ti}, \mathrm{V}, \mathrm{Cr}$, $\mathrm{Fe}, \mathrm{Co}$, Ni приводит к снижению их удельного сопротивления. Это объясняется тем, что ионы переходных элементов в тетраэдрической решетке кубического селенида цинка замещают ионы $\mathrm{Zn}^{2+}$, эффективно залечивая вакансии цинка. Уменьшение удельного сопротивления исследуемых кристаллов с увеличением концентрации легирующей примеси можно объяснить уменьшением концентрации вакансий цинка.

В табл. 1 приведены значения удельного сопротивления кристаллов ZnSe:Ti, ZnSe:V, ZnSe:Cr, ZnSe:Fe, $\mathrm{ZnSe}: \mathrm{Co}$ и $\mathrm{ZnSe}: \mathrm{Ni}$ с концентрацией соответствующих примесей $2 \cdot 10^{18} \mathrm{~cm}^{-3}$. Величина удельного сопротивления этих кристаллов слабо зависит от типа легирующей примеси, что указывает на существование одинаковых механизмов электропроводности в них.

С целью выяснения природы центров, ответственных за электропроводность исследуемых кристаллов $\mathrm{ZnSe}: \mathrm{Ti}, \mathrm{ZnSe}: \mathrm{V}, \mathrm{ZnSe}: \mathrm{Cr}, \mathrm{ZnSe}: \mathrm{Fe}, \mathrm{ZnSe}: \mathrm{Co}$ и $\mathrm{ZnSe}: \mathrm{Ni}$, была измерена температурная зависимость темнового тока. На рис. 1 (кривая 1) приведена температурная зависимость темнового тока кристаллов $\mathrm{ZnSe}: \mathrm{Cr}$. Темновой ток $(I)$ этих кристаллов возрастал во всем интервале роста температуры $(T)$. Энергия активации уровней, ответственных за темновую проводимость, оказалась равной $E_{d}=0.65$ эВ. Энергии активации уровней, ответственных за темновую проводимость кристаллов $\mathrm{ZnSe}: \mathrm{Ti}, \mathrm{ZnSe}: \mathrm{V}, \mathrm{ZnSe}: \mathrm{Cr}, \mathrm{ZnSe}: \mathrm{Fe}, \mathrm{ZnSe}: \mathrm{Co}$ и $\mathrm{ZnSe}: \mathrm{Ni}$, приведены в табл. 1. Энергия активации, равная 0.6-0.66 эВ, соответствует межузельному цинку $\mathrm{Zn}_{i}^{+}$ в кристаллах $\mathrm{ZnSe}$ [11]. В процессе диффузии переходных элементов в кристаллы $\mathrm{ZnSe}$ их ионы занимают узлы цинка, что приводит к образованию межузельных донорных центров $\mathrm{Zn}_{i}^{+}$, обеспечивающих электронную проводимость кристаллов $\mathrm{ZnSe}: \mathrm{Ti}, \mathrm{ZnSe}: \mathrm{V}, \mathrm{ZnSe}: \mathrm{Cr}$, $\mathrm{ZnSe}: \mathrm{Fe}, \mathrm{ZnSe}: \mathrm{Co}$ и $\mathrm{ZnSe}: \mathrm{Ni}$.

Вытеснение катионов в междоузлия при легировании ионами переходных элементов было обнаружено и в низкоомных кристаллах $\mathrm{ZnSe}$, легированных индием. Результаты исследований температурной зависимости темнового тока кристаллов ZnSe: In:Cr также представлены на рис. 1 (кривая 2). Установлено, что электропроводность таких кристаллов контролируется донорами с энергией активации 0.39 эВ, которым соответствуют межузельные атомы индия $\operatorname{In}_{i}^{3+}$, тогда как в кристаллах $\mathrm{ZnSe}: \mathrm{In}$, не содержащих примеси переходных элемен- тов, электропроводность контролируется центрами $\mathrm{In}_{Z n}^{+}$ с энергией активации 0.03 эВ, локализованными в подрешетке цинка.

Полученные температурные зависимости темнового тока кристаллов ZnSe, легированных $3 d$-примесями, были использованы для расчета концентраций доноров и акцепторов. Для этого решалась система уравнений

$$
I=\frac{e \mu U S}{l} \beta^{-1} N_{c} \frac{N_{d}-N_{a}}{N_{a}} e^{-\left(E_{c}-E_{d}\right) / k T},
$$

где $\mu-$ подвижность электронов, $S, l-$ площадь поперечного сечения и длина кристалла, $U$ напряжение, $\beta$ - степень спинового вырождения, $N_{c}=2\left(2 \pi m_{n} k T / h^{2}\right)$ - эффективная плотность электронных состояний в зоне проводимости, $N_{a, d}-$ концентрации донорных, акцепторных центров, $E_{c}-E_{d}-$ энергия активации, $k$ - постоянная Больцмана. Значения $N_{a}, N_{d}, E_{c}-E_{d}$ входят в качестве неизвестных в систему уравнений (1), каждое из которых записывается

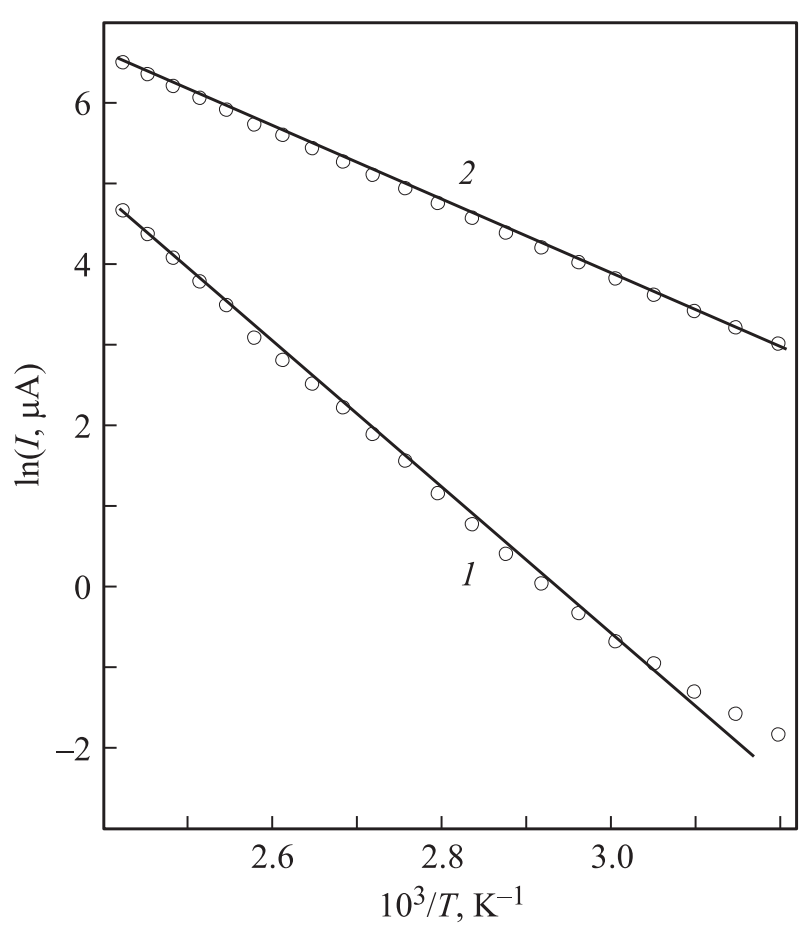

Рис. 1. Температурные зависимости темнового тока $I$ кристаллов $\mathrm{ZnSe}: \mathrm{Cr}(1)$ и $\mathrm{ZnSe}: \operatorname{In}: \mathrm{Cr}(2)$. 
Таблица 2. Глубина залегания основных состояний $3 d^{2+}$-ионов в кристаллах

\begin{tabular}{c|c|c|c|c|c|c|}
\hline Тип $3 d$-иона & $\mathrm{Ti}^{2+}$ & $\mathrm{V}^{2+}$ & $\mathrm{Cr}^{2+}$ & $\mathrm{Fe}^{2+}$ & $\mathrm{Co}^{2+}$ & $\mathrm{Ni}^{2+}$ \\
\hline Основное состояние & ${ }^{3} A_{2}(F)$ & ${ }^{4} T_{1}(F)$ & ${ }^{5} T_{2}(D)$ & ${ }^{5} E(D)$ & ${ }^{4} A_{2}(F)$ & ${ }^{3} T_{1}(F)$ \\
\hline Глубина залегания, эВ & 0.17 & 0.18 & 0.1 & 0.07 & 0.11 & 0.19
\end{tabular}

для заданного значения температуры и соответствующей ему величины тока, определенной из измерений температурной зависимости темнового тока.

Решения системы уравнений (1) для кристаллов $\mathrm{ZnSe}$, легированных $3 d$-примесями, представлены в табл. 1 . Из таблицы видно, что легирование кристаллов $\mathrm{ZnSe}$ примесями $\mathrm{Ti}, \mathrm{V}, \mathrm{Cr}, \mathrm{Fe}, \mathrm{Co}$, Ni приводит к росту концентрации доноров, в качестве которых выступают межузельные атомы цинка $\mathrm{Zn}_{i}^{+}$, что приводит к снижению удельного сопротивления образцов. Одновременно с ростом концентрации доноров наблюдается рост концентрации акцепторов. Поскольку при легировании $3 d$-элементами происходит эффективное замещение вакансий цинка, то в качестве компенсирующих акцепторов могут выступать ионы переходных элементов в зарядовом состоянии -1 [12,13]. Подтверждением достоверности полученных результатов расчета является то, что рассчитанные значения энергии активации $\left(E_{c}-E_{d}\right)_{\text {calc }}$ хорошо согласуются с соответствующими экспериментальными данными $\left(E_{c}-E_{d}\right)_{\exp }$ (табл. 1$)$.

\section{4. Анализ спектров фотопроводимости}

Спектры фотопроводимости кристаллов $\mathrm{ZnSe}$, легированных $\mathrm{Ti}, \mathrm{V}, \mathrm{Cr}, \mathrm{Fe}, \mathrm{Co}$ и $\mathrm{Ni}$, исследовались в температурном диапазоне $T=77-450 \mathrm{~K}$.

При $T=77 \mathrm{~K}$ спектры фотопроводимости всех исследуемых кристаллов характеризуются единственной узкой полосой фотопроводимости ( $B$-полоса), смещенной в область меньших энергий на 20-200 мэВ по отношению к полосе зона-зонной фотопроводимости нелегированных кристаллов, локализованной на 2.82 эВ. Величина этого смещения соответствует изменению ширины запрещенной зоны кристаллов $\mathrm{ZnSe}$, определенному по сдвигу края фундаментального поглощения этих кристаллов.

На рис. 2 представлены спектры фотопроводимости кристаллов $\mathrm{ZnSe}: \mathrm{V}$ с различной концентрацией примеси V, измеренные при температурах 300 и $400 \mathrm{~K}$. Установлено, что в низкоэнергетической относительно $B$-полосы области в спектрах фотопроводимости легированных переходными элементами кристаллов при температурах $300 \mathrm{~K}$ и выше, наблюдались серии пиков примесной фотопроводимости, интенсивность которых возрастала с увеличением концентраций легирующих примесей.

Первая полоса (II-полоса) при увеличении температуры кристаллов смещается в сторону меньших энер- гий (рис. 2). Величина этого сдвига сопоставима с величиной температурного изменения ширины запрещенной зоны ZnSe. Интенсивность данной полосы возрастает с увеличением концентрации легирующей примеси. Таким образом, можно сделать вывод, что $I_{\mathrm{I}}$-полоса обусловлена переходом электронов из основного уровня примесных ионов $\mathrm{Ti}, \mathrm{V}, \mathrm{Cr}, \mathrm{Fe}, \mathrm{Co}, \mathrm{Ni}$ в зону проводимости кристаллов. Сравнение положения максимума $I_{\mathrm{I}}$-полосы с положением линии зона-зонной фотопроводимости (B-полоса) позволило рассчитать глубину залегания основного уровня ионов переходных металлов в кристаллах $\mathrm{ZnSe}$ от потолка валентной зоны (табл. 2). Эта величина не зависит от концентрации примеси и температуры кристаллов.

Остальные полосы примесной фотопроводимости увеличивают свою интенсивность с ростом температуры кристаллов от 300 до $400 \mathrm{~K}$, однако положение их максимумов не меняется и совпадает с положением

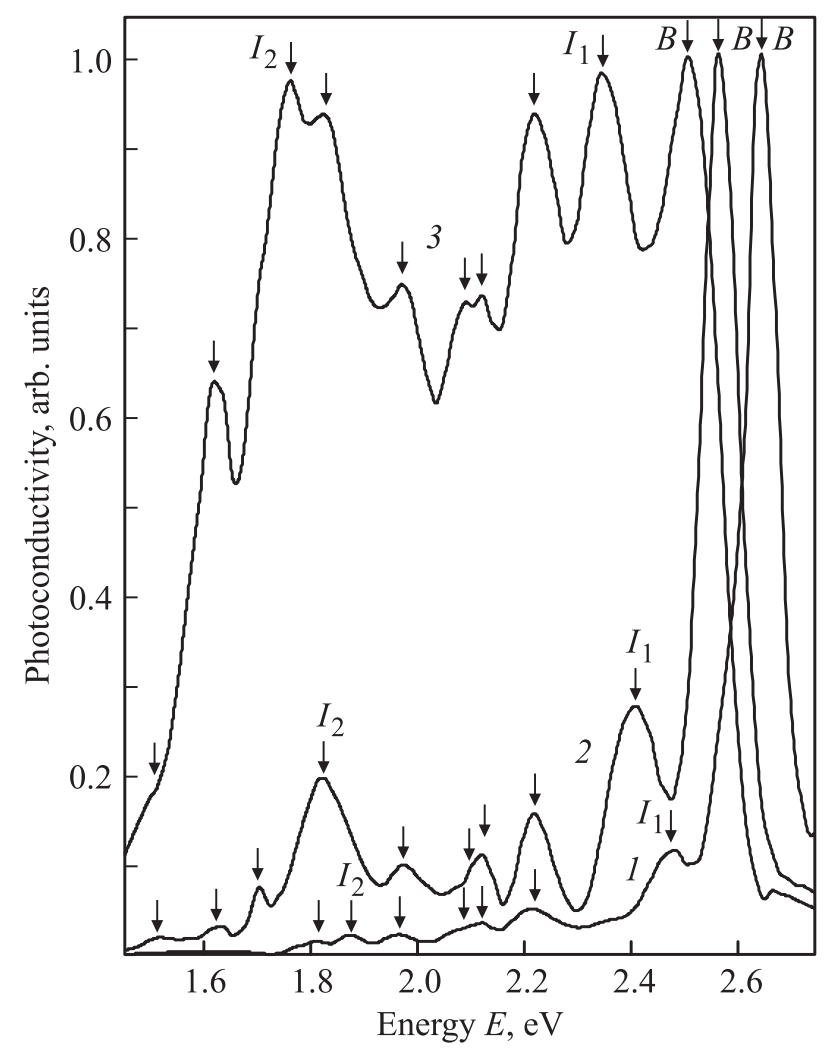

Рис. 2. Спектры фотопроводимости кристаллов $\mathrm{ZnSe}: \mathrm{V}$. Концентрация ванадия $10^{18}(1)$ и $4 \cdot 10^{19} \mathrm{~cm}^{-3}(2,3)$. Температура измерения $T=300(1,2)$ и $400 \mathrm{~K}(3)$. 
максимумов высокоэнергетических полос внутрицентрового поглощения исследуемых кристаллов, определенным в [6-10]. Увеличение концентрации примеси также ведет к росту интенсивности этих полос, без изменения их положения в спектре. Такое поведение выявленных полос свидетельствует о механизме фотопроводимости, включающем внутрицентровые переходы в пределах примесных $3 d^{2+}$-ионов. Это двухстадийный процесс, на первом этапе которого под влиянием поглощенных квантов света происходят переходы электронов в примесных ионах с основного уровня на возбужденные, а на втором этапе происходит тепловой выброс этих электронов в зону проводимости. В подтверждение этого следует отметить, что при $T<300 \mathrm{~K}$ полосы примесной фотопроводимости совсем не наблюдалось. Электронный тип фотопроводимости был подтвержден измерениями знака термоэдс исследуемых кристаллов.

Интенсивные полосы в ближней ИК области (I 2 -полосы) (рис. 2) в спектрах фотопроводимости кристаллов, легированных никелем и ванадием, соответствуют фотоионизационному процессу, в результате которого эти $3 d^{2+}$-ионы превращаются в $3 d^{+}[12]$.

\section{5. Заключение}

Проведенные исследования позволяют сделать следующие выводы.

- Показано, что ионы Ti, V, Cr, Fe, Co и $\mathrm{Ni}$ не принимают участия в электропроводности исследуемых кристаллов. Электропроводность кристаллов $\mathrm{ZnSe}$, легированных ионами переходных металлов, контролируется собственными донорами, в качестве которых выступают межузельные ионы $\mathrm{Zn}_{i}^{+}$.

- Снижение удельного сопротивления кристаллов $\mathrm{ZnSe}$ при легировании ионами переходных металлов объясняется залечиванием собственных дефектов акцепторной природы - вакансий цинка - и вытеснением атомов цинка в междоузлия с образованием донорных центров $\mathrm{Zn}_{i}^{+}$.

- Кристаллы $\mathrm{ZnSe}$, легированные ионами переходных металлов, обладают высокотемпературной электронной примесной фотопроводимостью, обусловленной внутрицентровыми переходами электронов в пределах примесных центров, с последующим тепловым добросом их в зону проводимости.

- Определены энергетические положения уровней основных состояний ионов $\mathrm{Ti}_{\mathrm{Zn}}^{2+}, \mathrm{V}_{\mathrm{Zn}}^{2+}, \mathrm{Cr}_{\mathrm{Zn}}^{2+}, \mathrm{Fe}_{\mathrm{Zn}}^{2+}, \mathrm{Co}_{\mathrm{Zn}}^{2+}$, $\mathrm{Ni}_{\mathrm{Zn}}^{2+}$ в кристаллах селенида цинка.

\section{Список литературы}

[1] V.V. Fedorov, S.B. Mirov, A. Gallian, D.V. Badikov, M.P. Frolov, Yu.V. Korostelin, V.I. Kozlovsky, A.I. Landman, Yu.P. Podmar'kov, V.A. Akimov, A.A. Voronov. IEEE J. Quant. Electron., 42 (9), 907 (2006).

[2] I.T. Sorokina, E. Sorokin, S.B. Mirov, V.V. Fedorov, V. Badikov, V. Panyutin, K. Schaffers. Optics Lett., 27, 1040 (2002).
[3] A.N. Avdonin, G.V. Kolibaba, D.D. Nedeoglo, N.D. Nedeoglo, V.P. Sirkeli. J. Optoelectron. Adv. Mater., 7 (2), 733 (2005).

[4] C. Kim, J.M. Peppers, D.V. Martyshkin, V.V. Fedorov, S.B. Mirov. Proc. SPIE, 7193, 71932R (2009).

[5] T. Konak, M. Tekavec, V.V. Fedorov, S.B. Mirov. Opt. Mater. Express, 3 (6), 777 (2013).

[6] Ю.А. Ницук. ФТП, 48 (2), 152 (2014).

[7] Ю.А. Ницук. ФТП, 47 (6), 728 (2013).

[8] Ю.Ф. Ваксман, Ю.А. Ницук, В.В. Яцун, А.С. Насибов, П.В. Шапкин. ФТП, 44 (2), 149 (2010).

[9] Ю.Ф. Ваксман, Ю.А. Ницук, В.В. Яцун, А.С. Насибов, П.В. Шапкин. ФТП, 44 (4), 463 (2010).

[10] Ю.Ф. Ваксман, В.В. Павлов, Ю.А. Ницук, Ю.Н. Пуртов, А.С. Насибов, П.В. Шапкин. ФТП, 40 (7), 815 (2006).

[11] В.А. Касиян, Д.Д. Недеогло, Н.Д. Недеогло. Неорг. матер., 37 (2), 168 (2001).

[12] J.M. Noras, J.W. Allen. J. Phys. C: Solid State Phys., 13 (18), 3511 (1980).

[13] A. Zunger. Solid State Phys., 39, 276 (1986).

Редактор Л.В. Шаронова

\section{Electrophysical properties of ZnSe crystals doped with transition elements}

\author{
Yu.A. Nitsuk, Yu.F. Vaksman \\ Odessa I.I. Mechnikov National University, \\ 65082 Odessa, Ukraine
}

Abstract The electrical conductivity and photoconductivity of ZnSe single crystals doped with transition element ions are investigated. It is shown that doping zinc selenide crystals with impurities of $3 d$-elements does not lead to formation of electrically active levels of these impurities. However, the introduction of impurities in the cationic sublattice result in formation of own electrically active defects. It is found that $\mathrm{ZnSe}: \mathrm{Ti}, \mathrm{V}, \mathrm{Cr}, \mathrm{Fe}, \mathrm{Co}, \mathrm{Ni}$ crystals possess high-temperature impurity photoconductivity. The photoconductivity mechanisms in these crystals are proposed. By the position of first ionization photoconductivity band the energies of $3 d^{2+}$ ions ground states in zinc selenide crystals are determined. 